\title{
Rethinking healthcare building design quality: an evidence-based strategy
}

\section{Grant R. W. Mills, Michael Phiri, Jonathan Erskine \& Andrew D. F. Price}

To cite this article: Grant R. W. Mills, Michael Phiri, Jonathan Erskine \& Andrew D. F. Price (2015) Rethinking healthcare building design quality: an evidence-based strategy, Building Research \& Information, 43:4, 499-515, DOI: 10.1080/09613218.2015.1033880

To link to this article: http://dx.doi.org/10.1080/09613218.2015.1033880

$$
\begin{aligned}
& \text { (c) } 2015 \text { The Author(s). Published by Taylor \& } \\
& \text { Francis }
\end{aligned}
$$

冓 Published online: 12 May 2015.

Submit your article to this journal $\pi$

Llll Article views: 900

Q View related articles ¿

View Crossmark data $\asymp$ 


\title{
RESEARCH PAPER
}

\section{Rethinking healthcare building design quality: an evidence-based strategy}

\author{
Grant R.W. Mills ${ }^{1}$, Michael Phiri ${ }^{2}$, Jonathan Erskine ${ }^{3}$ and Andrew D. F. Price ${ }^{4}$ \\ ${ }^{1}$ Bartlett School of Construction and Project Management, University College London, \\ 1-19 Torrington Place, London WC1E 7HB, UK \\ E-mail: g.mills@ucl.ac.uk \\ ${ }^{2}$ School of Architecture, University of Sheffield, Arts Tower, Western Bank, Sheffield S10 2TN, UK \\ E-mail: m.phiri@sheffield.ac.uk \\ ${ }^{3}$ Centre for Public Policy and Health, School for Medicine, Pharmacy and Health, Durham University, \\ Queen's Campus, Stockton-on-TeesTS176BH, UK \\ E-mail: jonathan.erskine@durham.ac.uk \\ ${ }^{4}$ Department of Civil and Building Engineering, Loughborough University, Loughborough LE11 3TU, UK \\ E-mail: a.d.f.price@lboro.ac.uk
}

\begin{abstract}
Healthcare buildings play a significant role in delivering healthcare services and outcomes (e.g. quality, suitability, cleanliness, patient experience, value for money and risk mitigation). However, the current diffusion of responsibilities in England between central government and healthcare trusts has created gaps and weaknesses in the evidence base, knowledge, skills and tools for creating and assessing healthcare building design quality. How can a national healthcare building design quality improvement strategy be created? This question is explored in relation to policy, strategy and organizational issues. Four evaluation studies and four action research studies indicate the complexity and responsibilities in defining a design quality improvement strategy. It is found that the interdisciplinary development of national standards and tools requires centralized investment to facilitate nationwide learning and improvements in evidence and outcomes. In addition, the inevitable health policy changes made by successive governments require a sustainable and strategic response. The creation and maintenance of capacity and capabilities will require a dedicated team of professionals and a wide interdisciplinary network of long-term contributors who are motivated by a long-term desire to improve healthcare building design quality.
\end{abstract}

Keywords: assessment tools, design guidance, design quality, healthcare buildings, public policy, outcomes, quality assurance, standards, strategy

\section{Introduction}

The National Health Service (NHS) in England is today an organizationally complex environment, subject to frequent shifts in policy and overseen by a mix of regulatory authorities (NHS England, 2015). The effects of the reforms resulting from policy changes are routinely subject to high-profile commentary and analysis (Edwards, Crump, \& Dayan, 2015; Gregory, Dixon, \& Ham, 2015) focusing mostly on issues such as access to healthcare services, quality and safety of clinical care, patient outcomes, staff satisfaction, finances and rationing of resources in a time of constrained budgets. In contrast, the role of the healthcare built environment, and its quality, receives much less attention (Edwards, 2013). In part, this is due to the inflexible nature of healthcare buildings, which typically have a lifespan measured in decades. But it is also the case that there are far fewer healthcare infrastructure professionals such as property and estates managers according to NHS workforce statistics (HSCIC, 2015) available to lobby for resources, compared with the number of clinicians 
and administrators, organized into professional associations and clinical colleges.

While the individuals and organizations responsible for the healthcare built environment may not enjoy as high a profile as others in the health system, they nonetheless have an equal responsibility to respond to the highly dynamic landscape of healthcare policy and practice. Furthermore, this responsibility means that the future healthcare building design quality improvement strategy should be based on a robust evidence base (Phiri, 2006; Sadler et al., 2011; Ulrich et al., 2004, 2008). Those who plan, design, construct and maintain the healthcare estate, and who are charged with its strategic development, therefore need access to an authoritative, expert source of information and guidance. In the past, such a resource was available from central government. For example, the Department of Health (DH) has historically had a strong role in initiating and facilitating evidencebased strategy to capture and disseminate evidence in England. However, following a number of organizational reconfigurations of the NHS in England, the key enabling role played by the $\mathrm{DH}$ has recently diminished, focusing evidence-based learning at a local NHS trust level, not at the level of national healthcare building standards and guidance. Against this background, two central questions emerge:

- How can a future strategy for improving quality and safety in healthcare facility design be established in a healthcare sector subject to frequently changing policy?

- How can there be national and long-term learning in the implementation of such a strategy to improve the evidence and quality of outcomes?

This article addresses these questions through a review of recent academic studies and the discussion of findings from eight studies which investigated evidencebased standards and strategic planning tools. To ensure consistent understanding through the article, three key definitions are provided:

- Health or healthcare policy is a government's planned course of action or a pledge made by an political party. Healthcare policies are concerned with delivering change to healthcare services, to improve the affordability and accessibility of high-quality care. They may change relatively quickly and frequently compared with the typically 60-year design life of buildings. Policies have various indirect influences on physical buildings and so will contribute to their technical, social and clinical sustainability.

- A national healthcare building design quality improvement strategy is a cross-organizational action plan that provides a shared interpretation of how research and development can respond to healthcare policy in order to maintain and sustain building design quality.

- Future national healthcare building design quality improvement scenarios are alternative descriptions of influencing factors and plausible futures that can support 'forward looking' (Godet, 1987). Scenarios can create alternatives and preparedness to address uncertainties. Scenarios most critically allow the elaboration of strategy (ways to work out scenarios) and can identify strategic gaps.

\section{Imperative for an emerging strategic response}

A strategy to improve the quality and safety of healthcare building design was implicit in the 1946 Act and subsequent launch of the NHS in 1948 (The National Health Service Act 1946). Apart from occasional periods of focused attention and accompanying capital expenditure, healthcare facility design and planning has since continued to have a largely lowprofile presence in high-level manifesto promises, the NHS Constitution (NHS for England, 2013) (which commits the NHS to ensuring 'that services are provided in a clean and safe environment that is fit for purpose, based on national best practice'), white papers and subsequent policy implementation initiatives (Secretary of State for Health, 2000; Wanless, 2002). Decisions on design strategy for healthcare buildings are rarely of the highest priority for health policy-makers, resulting in the past in somewhat fragmented and disconnected mechanisms for national healthcare building design quality improvement. This article demonstrates how academics and practitioners can work together to address policy challenges through the ongoing development of design quality strategy.

Healthcare policy and healthcare building strategy have at times enjoyed greater and more explicit synergy, particularly during periods of significant capital expenditure on new buildings. For example, the 1962 'Hospital Plan' aimed to build 90 new hospitals, remodel 134 others and provide 356 improvement schemes over a 10 -year period (Ministry of Health, 1962). This plan was revised in 1966 into the 'Hospital Building Programme', followed by the Harness and Nucleus hospital building programmes in the 1970s and 1980s and the Private Finance Initiative (PFI)/Public-Private Partnership (PPP) hospital building schemes of the 1990s and 2000s. The centralized DH-coordinated capital programmes resulted in the prolific development of new standards and tools. These have contributed an evidence and experience base, common benchmarks and level of rigour 
in methodology which is evident from the Health Building Notes (HBNs) developed at the time.

Significant capital building programmes have driven the development of standards, guidance and tools aimed at the successful delivery and achievement of specific quality outcomes. However, the current economic climate makes large-scale national investment programmes unlikely for the foreseeable future. A low rate of new-build replenishment (estimated at less than $4 \%$ of the total NHS estate) is an underlying problem. In reality, many existing healthcare buildings suffer from under-investment in maintenance and require significant upgrading (Mills et al., 2015). To deliver success, any healthcare building design quality improvement strategy must acknowledge these realities beyond association with only new-build hospital programmes.

Academic attention has recently focused on the future direction of a more sustainable strategy. For example, research by Lindahl et al. (2010), Phiri, Mills, Chan, and Price (2011) and Mills et al. (2012) has examined healthcare building planning and development of strategies for design quality improvement. Barlow and Koberle-Gaise (2008) and Barlow et al. (2011) have investigated the impact of building finance and procurement models on healthcare policy. They found that the potential for buildings to accommodate future service change and innovation is restricted by private finance models. Significant within the healthcare sector has been the basis of systematic evidencebased knowledge that has supported tool development (Phiri, 2014).

This background suggests a need to re-examine the interrelationships between existing organizations involved in healthcare policy and building design quality improvement, and to take an interdisciplinary approach to evidence-based design. This approach could continue to inform the dynamic relationship between healthcare infrastructure inputs, clinical outputs, patient outcomes and responsibilities shared across actors in the legislative framework (Figure 1).

In 2010/11, the NHS England building portfolio had a capital value of $£ 83$ billion ( $€ 106$ billion) and operating costs of $£ 7.2$ billion ( $€ 9.2$ billion) according to Estates Return Information Collection (ERIC) data (HSCIC, 2015). So significant are these capital and operational resources that design quality improvement should be approached strategically and not be unduly diverted by short-term policy.

Strategy has been described as a means to create a bridge between 'loose coupled' organizations (Weick, 1969), such as those which comprise the NHS. This suggests that a national healthcare building design quality improvement strategy should be developed and supported to address the strengths and weaknesses of possible future scenarios. It may also support the formation of 'communities of practice' and create networks which transcend the boundaries of organizations (Brown \& Duguid, 1991, 2001) and so create national (and potential for international) knowledge sharing. Furthermore, a stronger and more cohesive strategy for collecting evidence, experience and learning from best practice will almost certainly improve building quality. Baldwin, Cave, and Lodge (2012) described this type of smart, network-based policy system as involving a mix of institutions and instruments, and a move from measuring input alone (such as return on investment) to the evaluation of processes, outputs and outcomes.

Today, centralized responsibility for improving building design quality has been greatly diminished and the quality orientation has narrowed from a broad perspective of patient satisfaction to prioritizing compliance and quality control in terms of safety, suitability and cleanliness (Roberts, 2013). This leaves professional design institutions (some of which are themselves threatened by loss of resources) and individual NHS trusts to champion a design-related view of quality and patient experience. Perversely, however, the current opportunities to improve the evidence of design quality are greater than ever. These include harnessing new forms of evidence from big data, data mining and benchmarking, and researching large-scale capital funding programmes using longitudinal studies. This article starts to demonstrate how research can create an environment for evidence-based strategy.

In recent years, the context of healthcare building safety and design quality in England has moved towards a looser, more distributed model (Mills et al., 2012). This is due to the changed role of the $\mathrm{DH}$. It no longer has a significant role in defining standards, but instead has become a 'steward' for good practice. The DH

no longer intends managing estates guidance, placing a significant onus on the estates community, the associated supply chain, and other healthcare personnel, to formulate and steer such guidance in the future.

(Roberts, 2013, p. 23)

Independent arm's-length bodies such as the National Institute for Health and Care Excellence (NICE) provide guidance and quality standards, while regulators such as the Care Quality Commission (CQC) and Monitor now assume responsibility for quality and safety, but without responsibility for programmes of (continuous) improvement. At the same time, the costs, resources and technical expertise - people, intellectual property (IP) and information technology (IT) 


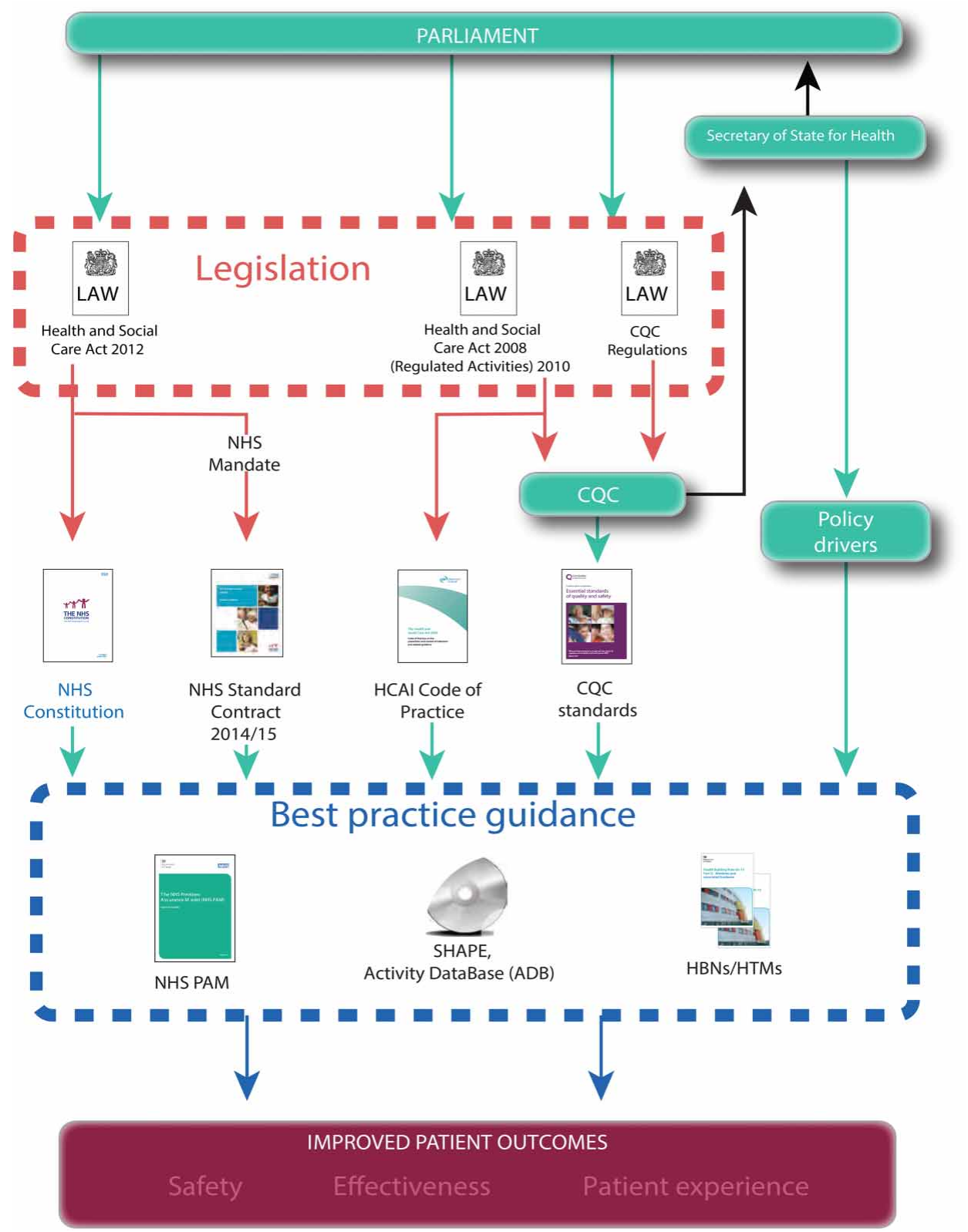

Figure 1 Health building legislative framework for England Source: Department of Health (2014)

- required to maintain existing healthcare building quality standards have been dispersed under the auspices of rationalization, producing some unintended, and as yet poorly understood, consequences. A review by the European Health Property Network (EuHPN) (2010) funded by the DH found that many European Union countries had experienced change in organizational structure from centralized to decentralized, or vice versa. As health systems and associated health policy changes, so too must the healthcare design quality improvement strategy, such that it remains adaptive and responsive to these changes.

\section{Method}

A mixed action and evaluation approach has been taken to answer the question: how can a sustainable national strategy for healthcare building design quality improvement be developed? A longitudinal study combined evaluation interviews and workshops to investigate evidence-based standards and tools (Studies A-D). Direct action research was undertaken to develop new strategic planning tools (Studies E-H). These tools were intended to have 'a direct and immediate impact' (Easterby-Smith, Thorpe, \& Lowe, 2002). In order to address the research question, 
both processes and outcomes were investigated (Langley, 2007; Pettigrew, Woodman, \& Cameron, 2001) using a case study method to deal with a wide and complex range of issues (Yin, 2003) and contexts (Langley, 1999). All the studies are defined in Table 1.

An interdisciplinary sample design was applied (stratified as in Table 1) using a mix of non-probability sampling techniques. The sample was an expert sample, which focused on representatives from the healthcare property sector (both clients and providers) known for their expertise in relation to building design quality. The participants were also known to the research team (or involved by the steering group through snowball sampling). Some participants had previously been involved in research or had contributed to policy formulation and the development of standards, guidance and tools. There was some selective opportunistic sampling that was driven by the availability and willingness of participants. The application of action research supported the selection of technically expert participants and introduced a greater level of applicability, timeliness and relevance into the research design and supported higher levels of engagement and greater continued access. There was also some level of theoretical sampling applied, commonly used in grounded theory, which sees emergence and theoretical completeness as the purpose of the study.

In order to draw comparisons between studies, the analysis followed basic grounded theory guidelines, using taped and transcribed interviews, coding, memo-writing, and sampling for theory development. This utilized Charmaz's (2006) 'flexible guidelines, not methodological rules, recipes and requirements' (p. 9), and methods and tools to gather rich, detailed and full data in relevant situational and social contexts.

A structured and systematic approach to coding and theme abstraction (Krippendorff 2004; Miles \& Huberman, 1994; Strauss \& Corbin, 1998) provided the basis for data analysis. To ensure reliability, transcriptions were independently evaluated by multiple investigators and validated by a steering group of practitioners.

This approach was appropriate to address the complex healthcare context, characterized by many and varied mixed relationships between organizational structures, strategies, interventions, standards, guidance and tools. In the past, traditional command-and-control arrangements have helped create a purposeful system; however, constrained resources are now forcing change and there is a need to operate within a dynamic system of strategy formation that is responsive to potential future scenarios. Three such scenarios (1-3) were explored to test these complex interdependencies (Figure 2). These scenarios emerged from the action research and were selected on the basis that they were plausible, structurally different, overall consistent, insightful and challenging (Wilson, 1998, p. 91):

- Scenario 1: Raise awareness of the importance of central government $(\mathrm{DH})$ command and control in driving improvements to healthcare building design quality.

- Scenario 2: Build a shared responsibility for healthcare design quality improvement and interdisciplinary cooperation amongst stakeholders that acknowledges limited resources and reduced central government $(\mathrm{DH})$ funding and absence of DH command and control.

- Scenario 3: Develop a wider delivery system of quality assurance based on new knowledge generated through externally funded research and its subsequent exploitation.

Scenario 1 represents the situation where all actors involved in a hospital building programme are led by a central, government authority. In this scenario it is perceived as relatively straightforward to identify and commission the correct technical expertise from a wide sample of institutions and develop new approaches that drive excellence in healthcare building quality.

Scenario 2 describes a dispersal of authority and accountability, and a reliance on multiple stakeholders acting for the overall good. This is typical of situations in which no major healthcare building programmes are being undertaken.

Scenario 3 concerns how and why new quality approaches might be developed in the future. Specifically, it focuses on how learning is achieved and incentivized through externally funded research and its subsequent exploitation. Critical to this is that quality improvements are made, new tools are developed and customized, and a truly open market enables NHS trusts or commissioning organizations to select providers on the basis of expertise.

\section{Data and findings}

\section{Review of existing healthcare building standards and tools}

In the context of shifting responsibilities for building design strategy and academic focus on how to ensure a sustainable future strategy, this article reports on lessons learnt from a systematic review of Health Building Notes (HBN) standards. This analysis formed part of Study B (Tables 1 and 3). The aim was to characterize the definition and content of these documents and their level of specificity and 
Table 1 Longitudinal study research design as evaluation (i) and direct action research (ii)

$\begin{array}{lll}\text { Name/date } \quad \text { Participants } & \text { Meeting purpose }\end{array}$

\section{(i) Evaluation meetings, interviews and workshops investigating regulation, standards, tools, research and challenges}
A. Healthcare Infrastructure Regulatory System and Department of Health Standards and Guidance Review Workshops (March 2009-November 2011) 1), $1 \times 5$ h. (Policy $n=3$, fund $n=$ 1), $1 \times 6$ h. (Policy $n=6$, design $n$ $=3$, healthcare planning $n=3$, tool developer $n=2$ )

B. Tool Review and Exploitation Workshops (April 2009November 2011) $(n=3), 2 \times 4$ h. Policy $(n=2), 2$ $\times 4$ h. (Clients $n=1$, contractor $n=1$, policy $n=2$, design $n=$ 3 , information and communication technology developer $n=2), 2 \times 4 \mathrm{~h}$. Policy $(n=2)$

C. Research Steering Group Workshops (June 2010March 2011)

$1 \times 6$ h. (Clients $n=2$, contractor $n$ $=1$, policy $n=4$, design $/$ engineer $n=6), 1 \times 6 \mathrm{~h}$. (Policy $n$ $=2$, design $n=2$, healthcare planning $n=3$ ), $1 \times 6$ h. (Policy $n$ $=1$, design $n=3$, healthcare planning $n=3$ )

D. Technical Specialization and Challenge Workshops (April 2011-May 2011)

$1 \times 6$ h (Policy $n=2$, design $n=4)$, $1 \times 6 \mathrm{~h}$ (Policy $n=1$, design $n=$ 9), $1 \times 6 \mathrm{~h}$ (Policy $n=2$, design $n$ $=12$, NHS client $n=2$ )

\section{(ii) Direct action research to develop new strategic planning tools}

Twelve workshops involving 32 participants from key policy, clinical, funding, regulation and construction supply chain stakeholders. These informed the transformation of the healthcare infrastructure regulatory system and supported the reform of the Department of Health standards and guidance. These meetings investigated existing methods, data and research

$1 \times 2$ h. Contractor $(n=1), 1 \times 3 \mathrm{~h}$.
Eight workshops involving 17 participants (April 2009-May 2011) with key policy and construction supply chain stakeholders reviewed a sample of existing tools in the policy environment. Reviews of tools included: AEDET/ASPECT/BREEAM and ADB/ TAHPI/Active Plan/BIM. The meetings specifically investigated the exploitability of methods

Three steering group workshops with 27 participants (June 2010March 2011) with key policy and construction supply chain stakeholders who directed the 'Evidence-Based Learning Environment' (EBLE) research into the application of EBD and other tools to support learning

Three challenge-based workshops involving 32 participants (AprilMay 2011) tested the implications of (1) elderly, vulnerable, mental health and dementia, (2) reconfiguration/refurbishment and (3) children/third/independent sector provision for the regulatory system. This work aimed to contribute knowledge on how the definition of standards could respond to the uniqueness and complexity of specific user groups, the technical and specialist services differences in clinical conditions, and the impact of building age and private/third sector procurement
E. Tool 1 Development Strategic Planning (May 2009-November 2010)

F. Tool 2 Development Strategic Planning (February 2012-January 2013)

G. Tool 3 Development Strategic Planning (January 2013-April 2013)

Eight workshops and three steering

Three workshops and seven

H. Tool 4 Development Strategic Eight workshops and four steering Planning (November 2009on-going) group meetings involving over 77 participants developed the Premises Assurance Model (PAM) interviews with 34 directors of estates and facilities and five Department of Health representatives

wo workshops, five four workshops involving 182 participants developed Planning Healthcare approach to (PHI), a facilitated SHAPE groups involving 141 participants on research into the design of accident and emergency (A\&E) using open-scenario planning
$2 \times 3 \mathrm{~h}$. Review of SHAPE $(n=31$ including policy, transport planners, tool developers, healthcare clients, designers). The PHI framework and approach was developed through grounded theory analysis, including multi-stakeholder presentations and observation involving $62 \mathrm{~h}(n=32)$. Baseline data on care, estates and transport were gathered from five independent case study sites, desk-based reviews, multi-participant memoing and five multidisciplinary workshops $(n=119)$. Four scenario-based behavioural simulations on four case studies. SHAPE application case study $(20 \mathrm{~h})$ and three 2 -h interviews. Link to local transport time analysis. Review and modelling of hospital episode statistics

PAM was developed from 3-4-h workshops to direct its development $(n=17)$. Three specific mental health, primary care and acute trust validation workshops $(n=7)$ plus a Delphi reviews with all participants and seven 5 -h workshops with multidisciplinary stakeholders $(n=53)$

Critical Infrastructure Risk (CIR) was developed from three 2-4-h workshops to direct the development of new CIR analytics ( $n=$ 17) and detailed analysis of the dynamic situation of trusts' $\mathrm{CIR}$ strategies $(n=15)$. Qualitative interviews with directors of estates and facilities $(n=7)$ on self-reported backlog maintenance, with a focus on high and significant risk

A new open scenario planning approach was developed from eight case study workshops $(n=5,9,5,14,7,8,5$ and 7$)$ from seven acute trusts and four steering groups ( $n=23,16,23$ and 19) from across secondary, primary and mental health 


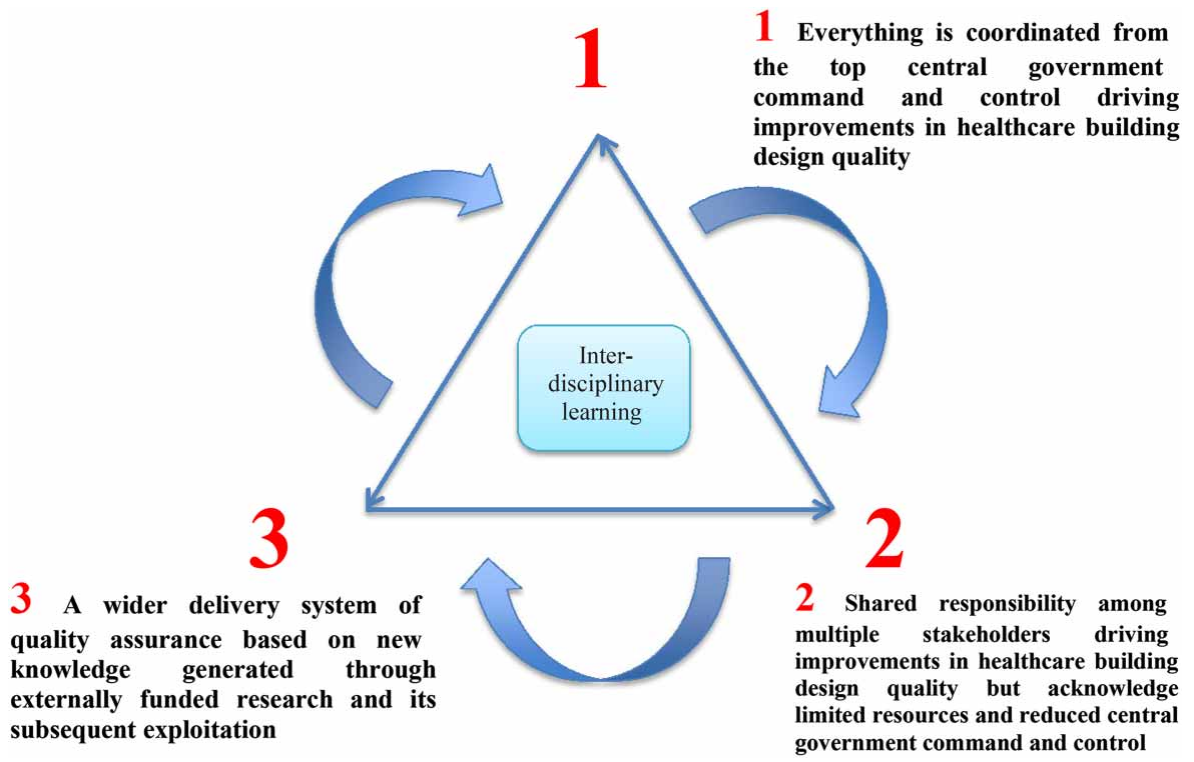

Figure 2 Future national healthcare building design quality improvement scenarios

compliance. The triggers for new standards were many and varied, which may account for variability in their content and structure. Some were developed to respond to changing health policies, while others responded to new technologies, changing economics, catastrophes or legalities and risks. A detailed review of a sample of 17 (at a time when there were 76 HBNs in the DH series) found a mixed quality orientation. Most $(82 \%)$ gave a direct definition of the spatial requirements (e.g. room data sheets and technical space drawings, often defined directly as inputs such as measures of height, distance, volume, etc.). There were also many descriptions of outcomes. Descriptions of clinical processes were rare but were implicit in clinical adjacencies between spaces.

Table 2 shows that many tools were developed in the period 2000-09 (69\%) and maintained prior to 2009 (69\%), but that more recently there has been a complexity in the movement and transition of tools.
For example, the number of formal and informal withdrawals of funding is relatively high $(38 \%)$ with only a few key risk-based and assurance tools retained $(13 \%)$ directly by the $\mathrm{DH}$.

Four empirical studies (i.e. A-D, as detailed in Table 3 ) addressed the evaluation of policy and standards, tools, research, technical specialization and the potential challenges facing healthcare building design quality improvement. These highlighted (1) deficiencies in tool integration and (2) the need for healthcare planning to integrate early decision-making about configuration of clinical services and the scale, scope and distribution of built assets.

\section{Impact of national standards and tools on local outcomes}

The existing minimum standard design guidance and tools such as HBNs, Health Technical Memoranda

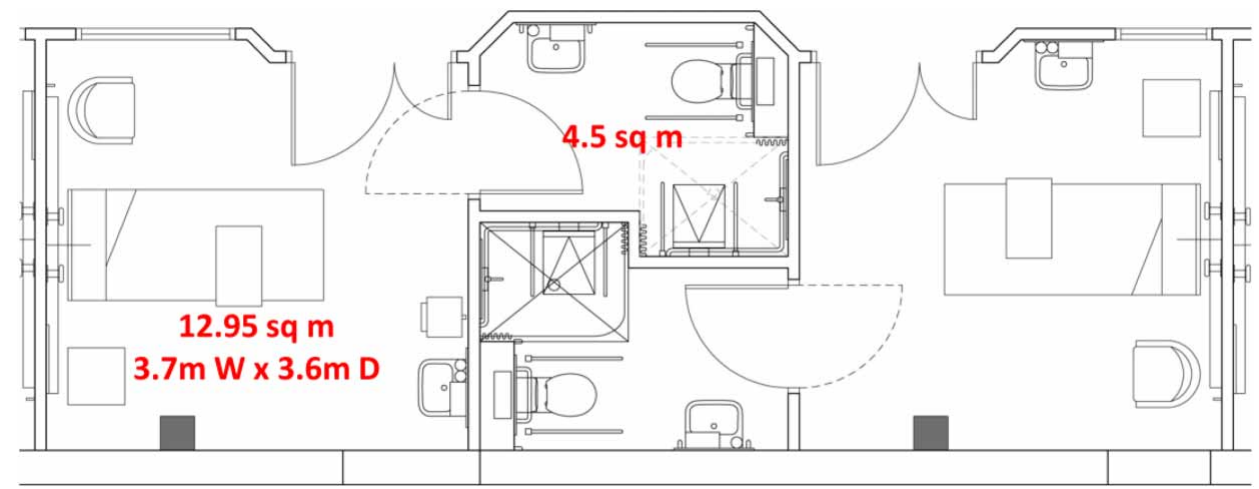

Figure 3 Refurbished single en suite rooms - Rotherham district hospital ward example 
Table 2 Review of national infrastructure planning, design and operation tools (2013 studies)

\begin{tabular}{|c|c|c|c|c|c|c|c|c|c|c|c|c|}
\hline \multirow[t]{2}{*}{ Tool } & \multirow[t]{2}{*}{ Reference } & \multirow[t]{2}{*}{ Contents } & \multicolumn{6}{|c|}{ Development and maintenance } & \multicolumn{4}{|c|}{ Status } \\
\hline & & & 임 & $\begin{array}{l}\text { ঃ } \\
\text { ণิ } \\
\text { ò } \\
\text { ᄋิ }\end{array}$ & $\begin{array}{l}\stackrel{\circ}{\circ} \\
\frac{\circ}{\circ} \\
\stackrel{\circ}{\circ}\end{array}$ & 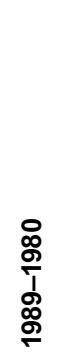 & 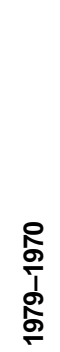 & 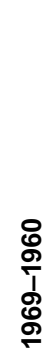 & 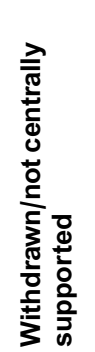 & 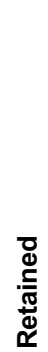 & 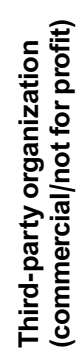 & 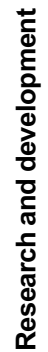 \\
\hline
\end{tabular}

\section{Design Tools}

Achieving Excellence

Design Evaluation

Toolkit (AEDET

Evolution)

Achieving Excellence

Design Evaluation

Toolkit (ASPECT)

Achieving Excellence
Design Evaluation Design Evaluation
Toolkit (BREEAM)

Activity DataBase (ADB)

$\mathrm{DH}(2008 \mathrm{c})$

$\mathrm{DH}(2008 \mathrm{a})$

TRE (1990)

BRE (1990)

$\mathrm{DH}(2012 \mathrm{~b})$

Inspiring Design

Excellence and

DH (2008b)

Achievements

(IDEAS)

Enquiry by Design (EBD)

The Prince's

Foundation for the

Built Environment

(2008)

Evidence-Based Design Center for Health

EBD

Design (1993)

\section{Operational audits}

Path Environment Audit Tool (PEAT)
Safety Agency
Functionality, Build Quality, Impact, Use,

Access, Space, Performance, Engineering

Construction, Character and Innovation,

Form and Materials, Staff and Patient

Environment, Urban and Social Integration

Privacy, Company and Dignity, Views, Nature

and Outdoors, Comfort and Control,

Legibility of Place, Interior Appearance,

Facilities, Staff

Management, Health and Wellbeing, Energy, Transport, Water, Materials and Waste, Land Use and Ecology and Pollution

Rooms, Activities, Personnel, Size Environment, Fittings

Exemplars, Database, Places, Geographic Location, Evidence

Stakeholder Engagement

Environment, Outcomes

Food, Cleanliness, Infection control, Patient Environment 


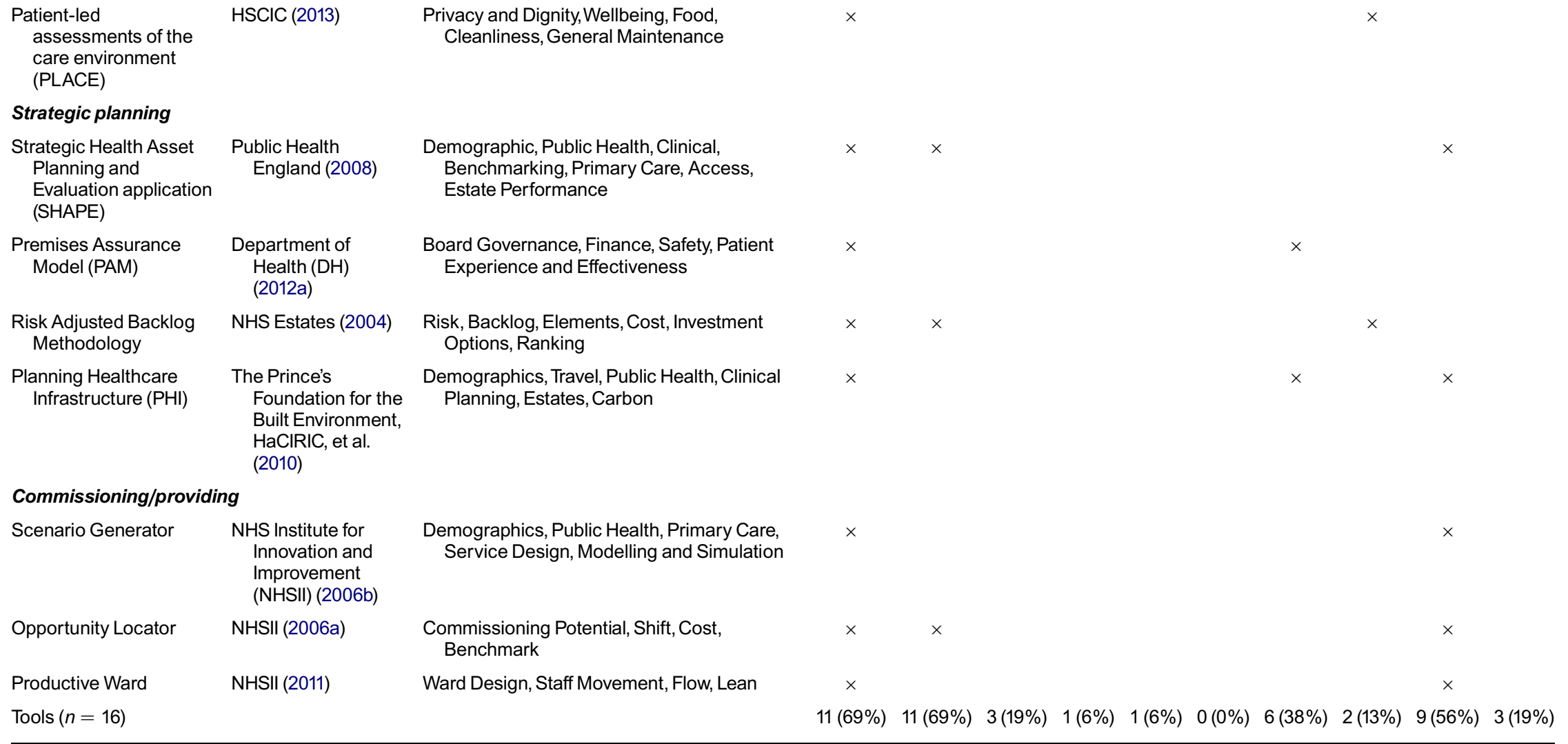


Table 3 Findings from meetings and interviews investigating regulation, standards, tools, research and challenges (2013, Studies A-D)

Policy challenges overcome by academics and practitioners working together

A. Healthcare Infrastructure Regulatory System and Department of Health Standards and Guidance Review Workshops

B. Tool Review and Exploitation Workshops

C. Research Steering Group Workshops

D. Technical Specialization and Challenge Workshops
Complex mix of regulatory standards, guidance and tools creates a confusing regulatory environment.

Significant numbers of standards have evolved over many years. Complex mix of risks and a lack of clarity on liabilities, compliance responsibilities and implications of maintenance, gaps and overlaps that may impact on safety, quality and innovation.

Transformation of the regulatory and policy environment has evolved with no understanding of estates and facilities quality and standards, and a need to drive greater awareness of the requirement to retain and grown competencies in this area.

No single healthcare infrastructure quality and safety tool to drive compliance, assurance and prevention.

Lack of information provided to regulators and policy-makers to monitor, report and benchmark premises assurance

A complex and diverse mix of tools is applied differently and with different structures and contents. Significant duplication between these tools requires rationalization. Significant work to map and align these tools allows for rationalization into PAM and so enhanced safety and quality assurance across NHS trusts in practice and supported efficient and effective application.

Limited tool maintenance and development. Analysis of existing tools drove funding for development and so impacts assurance, safety and quality

No existing multidisciplinary network to involve research alongside collaborators to inform policy and regulation.

Greater need for access to evidence and the creation of a peer network to share this information

Specific patient groups are not well represented in existing standards and guidance.

Impact of cultural values in building design is not well understood.

Health outcomes should be understood in healthcare planning to inform operational principles and scale, scope and distribution of estates and facilities.

Difficult to establish guidance for refurbishment as each setting is unique, and there could be a consequence if a lower (suboptimum) performance standard is set to cater for the constraints in dealing with existing buildings.

Sustainability and carbon is increasing in prominence and is supporting the creation of a purposeful system
(HTMs), Mechanical Engineering Specification (MES) and the Activity DataBase (ADB), which drive and define the quality of the healthcare environment, were mostly produced during periods of relatively high capital investment. The findings of Study D (Table 3), a review of the technical specialization and challenge workshops (addressing three critical social, economic and environmental issues identified by an interdisciplinary steering group), highlighted a shift in emphasis from a focus on new build (i.e. the PFI hospital building programme of the 2000s) to upgrading existing assets to improve standards and reduce running costs, and reconfiguring existing buildings to meet new healthcare delivery models.

There is still a question mark over the current application of standards, guidance and tools and the importance of their maintenance in periods of limited capital investment. For example, the refurbishment of Rotherham District Hospital comprised converting 35 beds (five six-bed wards and five single-bed rooms) to a new design that provided a 20-bed ward with eight single rooms and four three-bed rooms. The HBN 04 standard for single rooms, room sizing and the provision of en-suite facilities and nursing station views was a significant consideration, although the brief provided by the NHS trust and their strategic objectives and patient demands led to a decision that any reduction in the total number of beds was unacceptable. The client and design team decided that both (1) compliance with the national standard and (2) a formal derogation from the $\mathrm{DH}$ were not required due to the scale and scope of the works. A relaxed interpretation for the design of the single rooms was applied. A floor area of $12.95 \mathrm{~m}^{2}(3.7 \times$ $3.6 \mathrm{~m})$ was achieved. Whereas the national standard space allowance is $16 \mathrm{~m}^{2}$ (not including the en suite, which at $4.5 \mathrm{~m}^{2}$ complies with HBN 04). The unintentional consequence and resulting non-compliance has led to a design solution that may produce a suboptimal experience for patients and their visitors (Figure 3).

Other examples include Stepping Hill Hospital's (Stockport) refurbishment of a fourth-floor maternity block. This $£ 1$ million conversion was impacted by significant challenges to convert former wards (nine single rooms with no en suites and five four-bed bays) to four en-suite single rooms and six four-bed bays. The resulting design provided en-suite rooms but significantly 


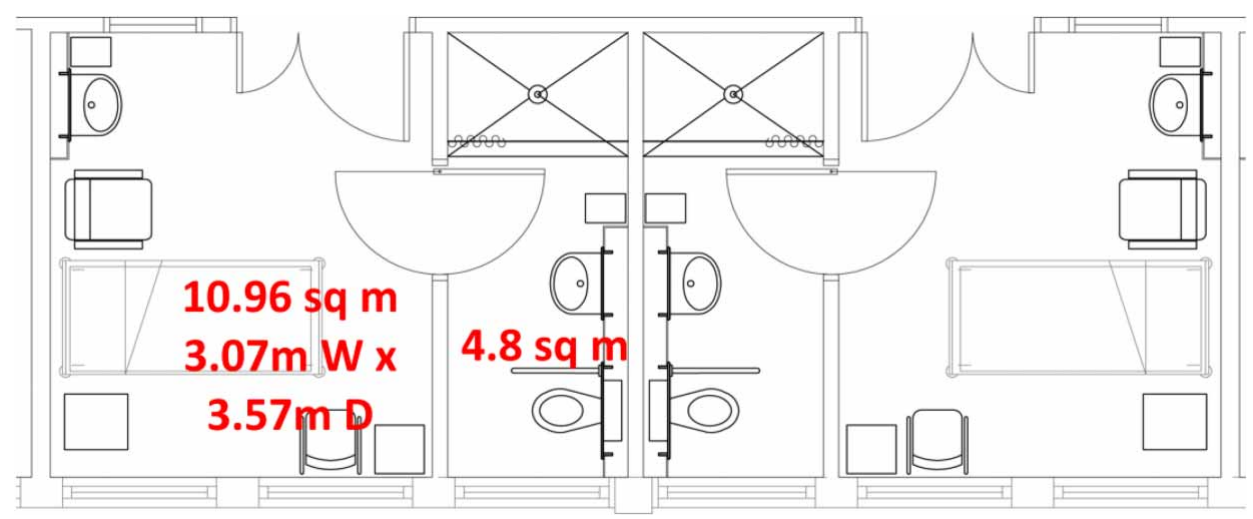

Figure 4 Refurbished single en suite rooms - Stepping Hill hospital, 4th floor maternity block example

compromised the floor area of each room, as shown in Figure 4.

The 'make do and mend' approach to healthcare architecture (after the UK Ministry of Information's Second World War slogan) may well be a practical and sensible response to tight budgets and lower expectations. However, this is not a position that sits well with strategic thinking and planning. Nor does it provide assurance of the quality of outcomes.

\section{Existing national strategy development}

The direct action research undertaken by the authors in the four empirical studies (E-H) has been described in Table 4. In these studies four new strategic planning tools were established to analyze the geographical access of healthcare buildings, assure building quality, eradicate critical backlog building risk and support scenario planning.

A complex mix of incentives and commercial sensitivities was found. Study E found excellent engagement of technical expertise and the advancement of modelling, including commercial exploitation of research. Perhaps unexpected was the complexity of problems in organizational and collaborative terms. Studies F and G found not only that a significant network could be leveraged by the $\mathrm{DH}$, including tools developed to support a broader and changing policy landscape, but also that under-resourcing and lack of commercial imperative contributed to missed opportunities and fractured relationships. Finally, Study $\mathrm{H}$ identified the need for long-term relationships to create an interdisciplinary approach.

\section{Impact of changing healthcare policy and organizational roles}

Study A (see Table 3) found that recent changes to the landscape of healthcare policy, and the roles assigned to organizations, had affected their ability to formulate strategies to address specific design quality issues. As the quotation below suggests, NHS trusts and commissioning agencies may not understand the changing landscape or appreciate their critical roles and responsibilities:

Cultural and attitude change is definitely an issue [...] it's up to an autonomous NHS, its professional advisors and industry to get together to co-produce [standards .... ] but it needs to have some branding of a sort that is recognized as being the industry leader, and impartial, and that's how our guidance is seen. (NHS trust manager)

Command-and-control strategies in the healthcare building design quality system are unlikely, because centralized capital resources are no longer available.

Indirect methods, as in Studies F and G (Table 4), are effective in benchmarking, guiding the system and 'nudging' trusts to take action. Tools such as the Premises Assurance Model (PAM) are providing data to arm's-length regulators and are benchmarking NHS trust spatial efficiency, but have yet to show how healthcare building design quality can be improved over time. Critical Infrastructure Risk (CIR) (Table 1) has demonstrated the risk to HM Treasury (the UK government department responsible for developing and executing public finance and economic policies) of existing NHS assets.

Funding to create and maintain a broad database of guidance and standards (through direct government action and monopolistic public ownership) is thought to be unaffordable due to limited centralized resources. A targeted, manageable set of guidance notes with an active and interdisciplinary peer network is a viable option. One advantage of a more decentralized approach is the strong interdisciplinary relationships and wider institutional contributions critical to the continued development of standards (Study H). This, if well managed, could create greater local learning and innovation. 
Another well-used strategy is a principle-based regime (through standards, guidance and tools), which defines outcomes but allows some freedom of response. Criticisms of such regimes are that they are open to manipulation, provide limited protection, and may not detect and allow the correction of poor performance.

Many stakeholders place considerable value on standards because of the centralized approach taken to their development and the implicit assurance provided by central government or authority:

To remove the development of standards from the DH will cost practices like ours [architects] a lot of money. [It is essential not to] lose the arm's-length body that the $\mathrm{DH}$ provides and the political direction/aim.

(Architect)

The same respondent stressed that, while the effects of removing a central authority are not immediately apparent, they will eventually materialize:

What we all know is that if we close the whole lot down tomorrow, it would not dramatically impact on anybody for at least three years.

Also usefully highlighted is the need to understand the rate of change of the content of standards and the triggers for change:

Now clearly radiology moves faster than potting sheds, but technology drives change, working practice drives change, and clinical policy and politics drive change.

(Healthcare policy-maker)

In summary, there is significant value in developing and maintaining national standards, and as a consequence, centralized resources are required.

\section{Future policy landscape and responsibilities for design quality strategy}

A variety of institutional and organizational structures are currently in place, as previously described with reference to national, regional and local organizational structures (Figure 1). Given the frequency of change and the use of arm's-length bodies (such as CQC and Monitor), a mix of institutional types is most probable in the future. Study F (Table 4) illustrates enforced self-/meta-regulation. The interdisciplinary nature of the PAM tool promotes risk sharing and ensures that the outcome is attuned to practice, while two leading institutions utilized a coordinated network for the sharing of information and a community of practice in its adoption. A range of data sets (ERIC, Hospital Episode Statistics (HES)), review processes (Gateway review and Commission for Architecture and the Built Environment (CABE) review) and tools (PEAT, PLACE and PAM) have also been developed to detect poor quality and non-compliance. However, the 'response', 'enforcement', 'assessment' and then 'modification' interventions have been deficient, with limited direct checking. Study A (Table 3) found that funders and agencies with oversight of finance and quality indicators may check and enforce compliance with a

Table 4 Findings from direct action research to develop new strategic planning tools (2013, Studies E-H)

Policy challenges overcome by academics and practitioners working together

E. Tool 1 Development Strategic Planning

F. Tool 2 Development Strategic Planning G. Tool 3 Development -
Strategic Planning

H. Tool 4 Development Strategic Planning
The customization of tools for a specific context and set of stakeholders requires specific competencies and abilities.

Organizational, commissioning and regional boundaries make information commercially sensitive and unable to be made openly available.

Care, estates and transport data lacks decision-making integration and scenario testing for regional reconfiguration (scale, scope and distribution).

Terms of collaboration and commercialization must be pre-agreed.

Data collection is complex and advanced visualization with a clear framework for decision-making is needed.

A changing political, regulatory and organizational landscape limited the position of the tool within a policy system.

Limited resources restricted the usability of the tool.

No commercial agenda and limited investment beyond that of the Department of Health.

Lack of long-term relationship management so research and development streams were fractured

Limited commercial imperative, so lack of investment in tool development.

Split between parties, with an alternative data set not integrated into the whole.

Development threatened by third-party commercial interests.

Under development of advanced and world-leading predictive-analytics solution.

Exploitable idea has been provided to third party. Missed opportunity for a joined-up approach.

Monopolization by lead commercial organization jeopardizes quality and restricts the involvement of experts. Lack of long-term relationship management so research and development streams are fractured.

Confusion and contractual intellectual property disagreements and lack of acknowledgement of contributions 
relatively narrow set of project-by-project measures, without a wider view or vital evidence checking across a series of projects or with those in other sectors:

because merchant bankers are probably riskaverse people, slavish adherence to standards which [may be outdated ...] so, everybody is comfortable that no one can be in trouble, but is it delivering what we really need? Is it cutting edge?

$$
\text { (Healthcare policy-maker) }
$$

The approach to standards and guidance currently in place to direct healthcare building design quality improvement lacks rigour. Until recently, preventative action was taken in the form of standards and guidance (e.g. measures to prevent or mitigate against catastrophic danger and major reactive resource uses). This is no longer an option because almost all these standards have now been archived and replaced with harm- and act-based actions - specifically those developed by the CQC, Monitor and the Health and Safety Executive (HSE), which inspect compliance with standards, health and safety, and risk. An interview in Study A found a lack of expertise to judge building quality, despite expert technical support from professional institutions. Without the coordinating role of the $\mathrm{DH}$, pressure to adopt a smart and interdisciplinary approach is put on others:

It is the approval process that sits behind these standards that is very important. This requires going to every clinical college to get sign off and buy in [ $\ldots$ it must be] inviting, it must allow anyone to feed into the process who wants to in the first group; however, the critical thing is $[\ldots]$ peer review.

Alongside some of these very instrumental things there is a network of people that are challenging and promulgating. It is the network that is most important, rather than the development of the standards - which does have a home alongside political change.

(NHS Trust Capital Development Manager)

As a consequence of political and structural change, the transition from one system to another is problematic:

$\mathrm{DH}$ are moving towards simpler accountability, but you are not making everything simpler actually harder for clients, who will be involved in huge costly debates, which extend the time that it takes to have a hospital designed and built.

(Leading healthcare architect)

All this may suggest that much more work is required to develop a system that overcomes complexity and fragmentation during transition. It also indicates that existing strong, open and interdisciplinary relationships will form a good starting point.

\section{Existing tools as a vehicle for policy transformation}

Tools play a vital role in supporting a healthcare building design quality improvement system (Table 2). Some tools measure generic outcomes (e.g. AEDET and ASPECT), with no formalized mechanism to benchmark quality centrally, while others are unresponsive to feedback and change. One tool (ADB) that facilitates a detailed and technical orientation to space (inputs) has been maintained for over 40 years but now suffers from a lack of development and investment to update data, frameworks and software. A stimulated open market (with customized software) would allow comparability, consistency and standardization.

Other tools have facilitated the wide-scale capture and maintenance of a robust and academic knowledge base. Evidence-based design (EBD) connects structural and process measures of the estate with patient/staff outcomes (Lawson \& Phiri, 2003). It indicates how the designed estate may impact on outputs such as length of hospital stay, trips and falls, rates of crossinfection, medical/medication errors, consumption of medication, as well as other detailed measures of heart rates, sleep patterns, staff absenteeism and the like. There are also links to qualitative outcome measures such as patient satisfaction and staff recruitment and retention. The advantage of these databases is that they are scientifically credible and, when kept up to date, stimulate continuous quality improvement.

Study C contributed directly to developing an evidence base, and supported access and peer feedback. Another example of an open systems approach has been design reviews facilitated by panels providing independent advice, such as the NHS Design Review Panel (DRP), the Gateway Review and the CABE Design Review (now managed by the Design Council). Strategic Health Asset Planning and Evaluation (SHAPE), which supports the strategic planning of services and physical assets across a whole health economy, is another example of an open system. Supported by a geographic information system (GIS), it combines benchmarks of existing national data sets of clinical activity, human geography and healthcare estates assets. Planning Healthcare Infrastructure (PHI), a methodology devised to facilitate wider stakeholder involvement in healthcare planning (Study E), has the potential to make this approach more flexible and usable, and the feedback more direct.

PAM is another open approach that allows process, output and outcomes to be benchmarked across NHS trusts. Advances in modelling and simulation are utilized in Scenario Generator, Opportunity Locator and the Productive Ward. Such tools are designed for 
use by experts, not novices. For example, Scenario Generator compares population and prevalence data (outcome data), cost (inputs) and activity (outputs) for generic pathways of care (mental health, urgent, planned and unplanned care). However, lack of technical expertise and significant cost often mean that these are closed system approaches. Others, such as Building Research Establishment Environmental Assessment Method (BREEAM) and Design Quality Indicator (DQI) for Health (superseding AEDET Evolution) are commercially applied (for a fee) by an open system of trained technical experts, while other more commercially exploited tools may deliberately take a closed (black box) approach to protect IP and market position. Both closed and open approaches exist, with open systems offering the greatest opportunity for interdisciplinary integration and continuous wholesystem learning.

\section{Discussion}

The evidence emerging from action research suggests that there is a need for a strategy to address the future of national healthcare building design quality improvement. This section identifies three scenarios that could improve communication, create a common language for learning and put in place a roadmap for strategic conversations within and between organizations (van der Heijden, 1996).

\section{Scenario 1: Raise awareness of the importance of central DH command and control in driving healthcare building design quality}

All studies $\mathrm{A}-\mathrm{H}$ found that the centralized functional role performed by $\mathrm{DH}$ has had a significant impact on learning, has created open feedback loops, has reduced duplication, has created economies of scale and scope, and has almost certainly improved the quality of outcomes while mitigating failure.

With regard to development of standards such as HBNs, the successful outcome of Study H suggests that an interdisciplinary peer network led by a clinical champion and supported by academics and practitioners should be used. But, perhaps most importantly this network must have the ability to innovate. This prompts opportunism that must be managed to ensure that individual incentives for innovation are balanced against longterm whole-system learning. Strategy is a bridge that builds sense between organizations and individuals and combines interdisciplinary systems (Weick, 1969). Interdisciplinary peer networks must therefore have freedom to incentivize the creation of 'communities of practice' between professional networks which transcend the boundaries of organizations (Brown \& Duguid, 1991, 2001), with the skills to build (Weick, 1969) and make sense (Gioia \& Chittipeddi, 1991).
An important question with regard to the maintenance or wholesale transfer of existing standards is whether organizations other than $\mathrm{DH}$ have the credibility to maintain interdisciplinary networks and the ability to incentivize innovative relationships. From the authors' experience in creating and maintaining such standards, the answer is quite often that they cannot. Rather, it is the skill of key individuals and the availability of unique and agile skills sets that will drive quality development in this case. This is best initiated by $\mathrm{DH}$, if only in part, and maintained by key credible individuals with interdisciplinary expertise in bridging and building sense between diverse specialities. The credibility and breadth of the resulting interdisciplinary representative network should prohibit the dominance of any single organization, and ensure deeper creative and critical reflection (Argyris \& Schön, 1978).

\section{Scenario 2: Build shared responsibility and interdisciplinary cooperation amongst stakeholders}

This scenario is concerned with the alignment of incentives and expertise in the development of hospital building design quality strategy. It specifically acknowledges the limited resources and reduced $\mathrm{DH}$ or central government funding. Study F identified the important role of accredited engineering institutions in attracting networks of professionals within an accreditation structure. These institutions seem to have been more stable than those within the policy landscape. Their involvement in shaping policy is important; however, without $\mathrm{DH}$ direction, arbitration and whole policy system championing, it is likely that clinical engagement may wane, monopolies may start to form and the purpose of the systems may erode.

Study G demonstrated that interdisciplinary sharing of accurate benchmarks may encourage appropriate development. However, there is a difficult tension. From a commercial viewpoint, Dale, Wiele, and Iwaarden (2007) describe the ultimate purpose of a firm as to become the 'supplier of choice' and to 'lock' themselves into their customers' mode of operation by becoming their 'sole supplier'. This is in opposition to the view of policy-makers, who see this as impacting on 'contestability' and 'value for money', so any new system must prevent 'cream-skimming', 'anti-competitive' and 'monopoly' behaviours (Baldwin et al., 2012). A wholly selfregulated system deals less directly with this tension.

Previously, IP was owned solely by the Crown (i.e. central government), but this position is no longer an option, with a greater need for flexible co-creation of value (Mont \& Lindhqvist, 2003) and open source publication. The relationship between stakeholders requires expertise in bridging knowledge domains, building sense and meshing technical competencies. This requires moving beyond an economic and topdown model to a new paradigm in which the 
system's ultimate goal is to serve patients (by meeting clinicians' expectations). Study $\mathrm{H}$ demonstrates a way in which this could be achieved. At an individual level, participants must be engaged and motivated by economic, social and psychological policy goals relating to personal fulfilment and must be directly recognized for their contributions. Studies E-H exhibited both successes and failures in this regard.

In terms of driving continuous learning, innovation and dynamic improvement, Study $\mathrm{H}$ demonstrates that this can be achieved through an open system of feedback - a system that trusts the judgement of experts, facilitates interdisciplinary working and places no expectation on static and optimized input, process, output or outcome alone. This supports Langley's (2007) proposal to investigate 'outcomes as inputs', continually monitor change and 'not forget outcomes are often rather artificial staging points amid never-ending processes' (p. 7).

\section{Scenario 3: Develop a wider delivery system of quality assurance based on new knowledge generated through externally funded research and its subsequent exploitation}

Previously, the DH has been successful in providing the seed-corn investment to 'nudge' tool development (Baldwin et al., 2012) without dis-beneficial market monopolization. This precedent makes for a dynamic and changing landscape of quality management tools, with some being formally or informally withdrawn, some transferred between organizations, and others undergoing research and development (Table 2). Resources must therefore be provided to manage such a portfolio of tools, which also requires greater expertise in managing IP, open-source development and commercial acumen than was the case in the past. Different models of funding may support innovation by promoting the spread of knowledge beyond existing silos into the next generation of talented professionals. However, in order to motivate and incentivize innovation, recognition of organizational and individual efforts is essential. Paying greater attention to managing IP would lead to new exploitation and greater demonstration of impact.

All studies $(A-G)$ found that while strong relationships are difficult to formulate and maintain over a long period, specific individuals with specialist expertise are highly motivated to hold together strong interdisciplinary networks and develop both evidence and expertise with relatively small financial incentives.

With few centralized resources to develop new design quality approaches, new forms of relationship are needed, in addition to the seed-corn funding of research and innovation and the generation of alternative revenue streams, for example, commercial tool development and licensing or the joining up of various research funding organizations

\section{Conclusions and recommendations}

As clinical and scientific practices develop and evolve, it is imperative to have an emerging strategy for healthcare facilities to develop a healthcare building design quality strategy that spans changing incoming governments. The existing healthcare design quality system has been successful in delivering a mix of regulatory strategies combining command-andcontrol, incentive-based, market-harnessed and design action. However, the role of standards and guidance and the recognition of key roles have been affected by a period of major structural change. There are clear opportunities now for meta- and self-regulation regimes and a mix of interventions, tools and networks that will reduce the burden of rewriting standards, acknowledge individual contributions (and so build a reputation for ongoing business development) and create a wider ownership of building design quality standards throughout the supply chain. Comparison with other countries in the European Union and Australia shows that many strategies for design quality improvement are similarly disrupted (EuHPN, 2010). England has an active network of interdisciplinary contributors which has been resilient to these changes. This network applies a mixed, smart and networked system that interlocks components to create learning and to encourage innovation and value for money through the efficient and effective engagement and incentivization of technical specialists. The following recommendations are made.

\section{Re-define and strengthen the critical role of central zed role of government (DH) in healthcare building design quality improvement strategy}

A centralized role (such as that undertaken by the $\mathrm{DH}$ ) has been highly effective in managing the complex relationships between public and private organizations (through direct standards development, gateway reviews and centralized procurement by way of PFI, Local Improvement Finance Trust (LIFT) and Procure21 (P21)) for example. In periods when major hospital building programmes have been underway quality has developed. However, when large programmes do not exist, periodic and ongoing strategy must emerge to leverage adequate resources to respond to changing health policy goals. Investment in ongoing evaluation and action-based research will trigger an evidence-based strategy.

During these periods, the task of lobbying government to provide leadership is easier and more straightforward with online technology, as can be seen in a 
recent building programme of 38 hospitals in Denmark, the website for which details the framework and terms for the building project, including information on the knowledge-sharing project (see www. godtsygehusbyggeri.dk).

Networks (with academia and institutions) should be more creative in establishing new collaborations to cope with political, economic and social upheavals, and to take advantage of advances in information and communication technology.

\section{Advocate and champion the development and adoption of open and dynamic standards, guidance and tools which also provide a robust response to contestable market forces}

Advanced, co-created systems of interdisciplinary relationships should be managed to create open and dynamic systems of peer knowledge and information exchange. Professional institutions and design consultants should lobby government to provide leadership and support for a manageable, minimal and standardized data set that avoids duplication, fragmentation, redundancy and repetition.

\section{Canvass the development of an appropriate and suitably funded evidence base to underpin tools for quality and safety improvement}

An interdisciplinary approach to evidence-based design must continue to inform relationships between healthcare infrastructure inputs, clinical outputs and patient outcomes. Adopting a rigorous evidence base underpinned by credible evidence, derived from scientific studies or well-designed research, establishes a source of authority, especially when contested by scientifically minded clinicians and policy makers. The challenge is to persuade decision-makers to support continuous improvements in design quality over and above more straightforward compliance with safety requirements.

\section{Acknowledgements}

The authors acknowledge those who participated in the questionnaires and focus groups, and others who supported and provided information.

\section{Disclosure statement}

No potential conflict of interest was reported by the authors.

\section{Funding}

The research was funded in part by Loughborough University ESPRC Innovative Manufacturing and Construction Research Centre [grant number EP/E002323/1] and EPSRC Health and Care Infrastructure Research and Innovation Centre core grants [grant numbers EP/D039614/1 and EP/I029788/1], in addition to funding from the Department of Health.

\section{References}

Argyris, C., \& Schön, D. (1978). Organizational learning: A theory of action and perspective. Reading, PA: AddisonWesley.

Baldwin, R., Cave, M., \& Lodge, M. (2012). Understanding regulation: Theory, practice, and strategy. Oxford: Oxford University Press.

Barlow, J., \& Koberle-Gaise, M. (2008). The private finance initiative, project form and design innovation: The UK's hospital programme. Research Policy, 37, 1392-1402. doi:10. 1016/j.respol.2008.04.027

Barlow, J., Koberle-Gaiser, M., Moss, R., Noble, A., Scher, P., \& Stow, D. (2011). Delivering innovation in hospital design: Finance, contracts and the institutional context. In M. Howard \& N. Caldwell (Eds.), Procuring complex performance: Studies of innovation in product-service management (pp. 159-173). New York: Taylor and Francis.

BRE (1990). BREEAM: How to get an assessment. Retrieved from http://www.breeam.org/page.jsp?id=530

Brown, J. S., \& Duguid, P. (1991). Organizational learning and communities-of-practice: Toward a unified view of working, learning, and innovation. Organization Science, 2, 40-57. doi:10.1287/orsc. 2.1.40

Brown, J. S., \& Duguid, P. (2001). Knowledge and organization: A social-practice perspective. Organization Science, 12, 198-213. doi:10.1287/orsc.12.2.198.10116

Center for Health Design (1993). Evidence Based Design (EBD). Retrieved March, 2013.

Charmaz, K. (2006). Constructing grounded theory. London: SAGE Publications Ltd.

Dale, B. G., Wiele, T. V. D. \& Iwaarden, J. V. (2007). Managing Quality. Chichester: Wiley-Blackwell.

Department of Health (DH) (2008a). A staff and patient environment calibration tool (ASPECT). Retrieved from http:// www.wales.nhs.uk/sites3/page.cfm?orgid $=254 \&$ pid $=7615$

Department of Health (DH) (2008b). Inspiring design excellence and achievements (IDEAs). Retrieved from http://www. wales.nhs.uk/sites3/page.cfm? orgid $=254 \&$ pid $=7616$

Department of Health (DH) (2008c). Achieving excellence design evaluation toolkit (AEDET Evolution). Retrieved from http://www.wales.nhs.uk/sites3/page.cfm?orgid=254\&pid= 7615.

Department of Health (DH) (2012a). NHS premises assurance model (NHS PAM). Retrieved from http://www.dh.gov.uk/ health/2013/01/nhs-pam/

Department of Health (DH) (2012b). Activity DataBase (ADB). Retrieved from http://www.wales.nhs.uk/sites3/page.cfm? orgid $=254 \&$ pid $=13867$

Department of Health (DH) (2014). Health Building Note 00-01. General design guidance for healthcare buildings. Retrieved from https://www.gov.uk/government/uploads/system/ uploads/attachment_data/file/316247/HBN_00-01-2.pdf

Easterby-Smith, M., Thorpe, R., \& Lowe, A. (2002). Management research: An introduction. London: Sage.

Edwards, N. (2013). NHS buildings: obstacle or opportunity. London: Nuffield Trust.

Edwards, N., Crump, H, \& Dayan, M. (2015). Rationing in the NHS. London: Nuffield Trust.

European Health Property Network. (2010). Guidelines and standards for healthcare buildings. Retrieved from http:// www.euhpn.eu/images/downloads/EuHPN_GandS.pdf

Gioia, D. A., \& Chittipeddi, K. (1991). Sensemaking and sensegiving in strategic change initiation. Strategic Management Journal, 12, 433-448. doi:10.1002/smj.4250120604

Godet, M. (1987) Scenarios and strategic management. London: Butterworth. 
Gregory, S., Dixon, A., \& Ham, C. (2015). Health policy under the coalition government. London: The King's Fund.

van der Heijden, K. (1996). Scenarios: The art of strategic conversation. Chichester: Wiley.

HSCIC. (2013). Patient-led assessments of the care environment (PLACE). Retrieved from http://www.commissioningboard. nhs.uk/2013/02/19/place/

HSCIC. (2014). NHS workforce statistics provisional statistics: National table. Retrieved from http://www.hscic.gov.uk on 24 February 2015.

HSCIC. (2015). NHS hospital estates and facilities statistics. Health and Social Care Information Centre. Retrieved from http://hefs.hscic.gov.uk on 24 February 2015.

Krippendorff, K. (2004). Content analysis: An introduction to its methodology. Thousand Oaks, CA: Sage Publications.

Langley, A. (1999). Strategies for theorizing from process data. The Academy of Management Review, 24, 691-710.

Langley, A. (2007). Process thinking in strategic organization. Strategic Organization, 5, 271-282. doi:10.1177/ 1476127007079965

Lawson, B. R., \& Phiri, M. (2003). The architectural healthcare environment and its effects on patient health outcomes. London: TSO.

Lindahl, G., Mills, G. R. W., Phiri, M., Fröst, P., Strid, M., \& Price, A. (2010). Quality innovation and evidence in healthcare physical environments in England and Sweden: Establishing a collaborative roadmap. In Proceedings of HaCIRIC10: Better health through better infrastructure. Edinburgh: HaCIRC.

Miles, M. B., \& Huberman, M. (1994). Qualitative data analysis: An expanded sourcebook. London: Sage Publications.

Mills, G. R. W., Deka, L., Price, A. D. F., Mahadkar, S., Pantzartzis, E. \& Sellars, P. (2015, forthcoming). Critical infrastructure risk in healthcare trusts in England: Predicting the impact of trust building portfolio age on the national condition of NHS assets. International Journal of Strategic Property Management, In Press.

Mills, G. R. W., Erskine, J., Price, A. D. F., Ricks, E., Phiri, M., \& Sellars, P. (2012). Developing a world-leading and smart regulatory design quality framework for healthcare estates in England. In Proceedings of HaCIRIC international conference: Transforming healthcare infrastructure and services in an age of austerity. Cardiff: HaCIRIC.

Ministry of Health. (1962). A Hospital Plan for England and Wales. Cmnd. 1604. London: HMSO.

Mont, O., \& Lindhquist, T. (2003). The role of public policy in advancement of product service systems. Journal of Cleaner Production, 11, 905-914. doi:10.1016/S0959. 6526(02)00152-X

National Health Service Act (1946). London: HMSO, 1946.

National Patient Safety Agency. (2000). Patient environment action teams (PEAT). Retrieved from http://www.nrls. npsa.nhs.uk/patient-safety-data/peat/

NHS England. (2015). Retrieved from http://www.nhs.uk/ NHSEngland/thenhs/about/Pages/nhsstructure.aspx on 23 February 2015.

NHS Estates. (2004). A risk-based methodology for establishing and managing backlog. London: HMSO.

NHS for England. (2013). The NHS constitution: The NHS belongs to us all. Retrieved from https://www.gov.uk/ Government/uploads/system/uploads/attachment_data/file/ 170656/NHS_Constitution.pdf

NHS Institute for Innovation and Improvement. (2006a). Opportunity locator. Retrieved from http://www.institute.nhs.uk/ index.php?option=com_joomcart\&main_page=document product_info\&products_id $=420$
NHS Institute for Innovation and Improvement. (2006b). Scenario generator. Retrieved from http://www.institute.nhs.uk/ scenariogenerator/general/what_is_the_scenario_generator. html

NHS Institute for Innovation and Improvement. (2011). The productive ward. Retrieved from http://www.institute.nhs.uk/ international/general/the_productive_ward.html

Pettigrew, A. M., Woodman, R. W., \& Cameron, K. S. (2001). Studying organizational change and development: Challenges for future research. Academy of Management Journal, 44, 697-713. doi:10.2307/3069411

Phiri, M. (2006). Does the physical environment affect staff and patient health outcomes? A review of studies and articles 1965-2006. London, TSO: Department of Health.

Phiri, M. (2014). Design tools for evidence-based healthcare design. Abington: Routledge.

Phiri, M., Mills, G. R. W., Chan, C.-L., \& Price, A. (2011). Facilitating infrastructure change in a time of austerity: Do building standards and guidance reflect the reality in designing for dementia, the elderly, children and single rooms. In Proceedings of HaCIRIC International Conference 2011, Global health infrastructure - challenges for the next decade: Delivering innovation, demonstrating the benefits (pp. 190211). Manchester: The Health and Care Infrastructure Research and Innovation Centre.

Public Health England. (2008). Strategic health asset planning and evaluation (SHAPE). Retrieved from http://shape.dh.gov.uk/

Roberts, P. (2013). Future guidance strategy explained. Health Estates: Journal of the Institute of Healthcare Engineering and Estates Management. January, 23-28.

Sadler, B. L., Guenther, R., Hamilton, D. K., Hessler, F. A., Merritt, C., Parkerm, D. (2011). Fable hospital 2.0: The business case for building better health care facilities. Hastings Center Report, 41, S13-S23. doi:10.1353/hcr.2011.0054

Secretary of State for Health (2000). The NHS plan: A plan for investment, a plan for reform. London: he Stationery Office Limited.

Strauss, A. L., \& Corbin, J. M. (1998). Basics of qualitative research: Techniques and procedures for developing grounded theory. London: Sage Publications.

The Prince's Foundation for the Built Environment. (2008). Enquiry by design for health: Design briefing for hospitals. Retrieved from http://www.princes-foundation.org/sites/ default/files/enquiry_by_design_for_health_-_design_ briefing__for_hospitals.pdf

The Prince's Foundation for the Built Environment, HaCIRIC, et al. (2010). Planning healthcare infrastructure (PHI). Retrieved from http://www.princes-foundation.org/whatwe-do/projects/engage/policy

Ulrich, R., Quan, X., et al. (2004). The role of the physical environment in the hospital of the 21st century: A once-ina-lifetime opportunity. Report to The Center for Health Design for the Designing the 21st Century Hospital Project, Available online at [accessed on 2013].

Ulrich, R. S., Zimring, C., Zhu, X., DuBose, J., Seo, H.-B., Choi, Y.-S., Quan, X. \& Joseph, A. (2008). A review of the research literature on evidence-based healthcare design. HERD Journal, 1, 61-125.

Wanless, D. (2002). Securing our future health: Taking a longterm view. London: HM Treasury.

Weick, K. E. (1969). The social psychology of organizing. Reading, MA: Addison-Wesley.

Wilson, I. (1998). Mental maps of the future. In L. Fahey \& R. Randall (Eds.), Learning from the future: Competitive foresight scenarios. New York: John Wiley.

Yin, R. K. (2003). Case study research: Design and methods. London: Sage Publications. 